\title{
Influence of aerosol lifetime on the interpretation of nucleation experiments with respect to the first nucleation theorem
}

\author{
S. Ehrhart and J. Curtius \\ Institute for Atmospheric and Environmental Sciences, Goethe University of Frankfurt am Main, Germany \\ Correspondence to: S. Ehrhart (ehrhart@iau.uni-frankfurt.de)
}

Received: 27 March 2013 - Published in Atmos. Chem. Phys. Discuss.: 12 April 2013

Revised: 18 August 2013 - Accepted: 10 September 2013 - Published: 26 November 2013

\begin{abstract}
The SAWNUC (Sulphuric Acid Water NUCleation) microphysical aerosol nucleation model is used to study the effect of reactor walls on the interpretation of nucleation experiments with respect to nucleation theory. This work shows that loss processes, such as wall losses, influence the interpretation of nucleation experiments, especially at low growth rates and short lifetimes of freshly nucleated particles. In these cases the power dependency of the formation rates, determined at a certain particle size, with respect to $\mathrm{H}_{2} \mathrm{SO}_{4}$ does not correspond to the approximate number of $\mathrm{H}_{2} \mathrm{SO}_{4}$ molecules in the critical cluster as expected by the first nucleation theorem. Observed $\partial \log (J) / \partial \log \left(\left[\mathrm{H}_{2} \mathrm{SO}_{4}\right]\right)$ therefore can vary widely for identical nucleation conditions but different sink terms.
\end{abstract}

\section{Introduction}

Nucleation of aerosol particles is a frequent phenomenon in the atmosphere (Kulmala et al., 2004). Losses of nucleating clusters and freshly formed particles to a population of preexisting particles are common to proceed in parallel to the nucleation and early growth of the freshly formed particles. Similarly, in laboratory experiments losses to the wall of the reaction vessel and the dwell time in flow tubes limit the lifetime of the newly formed particles. These artefacts cannot be avoided. Raes and Janssens (1986) used a detailed general dynamics model to correct their particle formation rates measured in chamber experiments. Kulmala et al. (2004) state that the "apparent" nucleation rate $J_{d}$ at a given threshold diameter $d$, defined as the derivative of particle concentration with respect to time, equals the "true" nucleation rate $J$ in systems without coagulation sinks. Here, "true" denotes the nucleation rate at the critical cluster size. Kerminen and Kulmala (2002) published an approach to take losses to preexisting particles into account when correcting from measured formation rates to particle formation rates at a certain smaller diameter, usually a presumed critical diameter. Nevertheless, this approach does not include losses of clusters below the critical size, nor does it include losses to vessel walls or the limited dwell time in flow tubes. For laboratory measurements, losses to walls of large chambers are usually assumed to be comparable to losses to pre-existing particles in ambient measurements (e.g. Kirkby et al., 2011), meaning the walls fulfil the same role as a population of large aerosol particles.

Studies on the influence of sinks on the nucleation rate have been published in the past. Becker and Reiss (1976) studied the effect of non-uniform conditions, or, to be more precise, the effect of monomers diffusing out of the region where nucleation is proceeding. McGraw and Marlow (1983) derived similar results with a different approach assuming a pre-existing aerosol concentration. Furthermore, McGraw and Marlow added an estimate under which conditions nucleation is influenced in a way that the condensation sink needs to be taken into account. McMurry et al. (2005) extended this approach and used it to determine whether new particle formation can be observed under atmospheric conditions. In this context it is important to note that the lowest detectable size of particles was then $3 \mathrm{~nm}$, while recent work decreased this value to sizes well below $2 \mathrm{~nm}$ (see, for example, Iida et al., 2009; Wimmer et al., 2013).

As will be shown here, these sinks can influence the interpretation of nucleation measurements with respect to the first nucleation theorem. 
Gas-phase sulphuric acid $\left(\mathrm{H}_{2} \mathrm{SO}_{4}\right)$ is considered to be the most important component in atmospheric aerosol nucleation (Weber et al., 1999; Curtius et al., 2006). The focus of this work is on the role of $\mathrm{H}_{2} \mathrm{SO}_{4}$, but the results are generally applicable to situations of aerosol nucleation with competing losses to walls or pre-existing particles. The first nucleation theorem states that the slope of $\log (J)$ as a function of $\log \left(\left[\mathrm{H}_{2} \mathrm{SO}_{4}\right]\right)$ gives approximately the number of $\mathrm{H}_{2} \mathrm{SO}_{4}$ molecules, $n^{*}$, in the critical cluster (Kashchiev, 1982; Oxtoby and Kashchiev, 1994). $n^{*}$ plays an important role for the microphysical interpretation of nucleation rate measurements. Currently, different experiments on binary nucleation yield widely varying numbers for $n^{*}$ in the range from 2 to 20 (see, for example, Wyslouzil et al. (1991), Viisanen et al. (1997), Ball et al. (1999), Sipilä et al. (2010), Kirkby et al. (2011) and Zollner et al. (2012)). Zollner et al. summarise the results in an overview table. One reason for these discrepancies can be the presence of contaminant vapours that cause ternary or multi-component nucleation and lower the freeenergy barrier for nucleation, and therefore lead to a smaller observed $n^{*}$. The significant influence of ammonia on nucleation rates was, for example, shown in Ball et al. (1999) and Kirkby et al. (2011).

In nucleation experiments two different design concepts are commonly used: flow tube and chamber. The biggest difference between both designs is that chambers usually have longer dwell times than flow tubes. The gas in a chamber can be stirred; in a flow tube it is usually in a laminar flow. The dominant loss effect for particles and $\mathrm{H}_{2} \mathrm{SO}_{4}$ in the case of the flow tube is the flow out of the reactor, resulting in an immediate stop of the nucleation and growth processes. In chamber experiments lifetimes of $\mathrm{H}_{2} \mathrm{SO}_{4}$ are typically determined by diffusion to the wall, and are usually of the order of several minutes.

In the present paper the SAWNUC model (Sulphuric Acid Water NUCleation (Lovejoy et al., 2004)) is used to determine the $n^{*}$ from simulated particle formation rates for different sizes of particles under conditions with and without wall losses present. SAWNUC is a microphysical model that describes binary aerosol nucleation and growth for neutral and ion-induced nucleation pathways of the sulphuric acid/water system.

The argumentation in McGraw and Marlow (1983) and in McMurry et al. (2005) is focused on the surface area of preexisting aerosols and condensation rates of monomers. Here we will use the lifetime of freshly nucleated particles and the experimentally more easily accessible growth rate to evaluate the validity of the nucleation theorem.

This work shows that for situations where loss rates become comparable to cluster growth rates (molecules s ${ }^{-1}$ ), the slopes of the logarithm of apparent nucleation rate, $\log \left(J_{d}\right)$, as a function of $\log \left(\left[\mathrm{H}_{2} \mathrm{SO}_{4}\right]\right)$ do not yield the approximate number of $\mathrm{H}_{2} \mathrm{SO}_{4}$ molecules in the critical cluster anymore. These losses can yield values of $n^{*}$ from the apparent nucleation rate that are much higher than the "true" $n^{*}$. This situation applies for many atmospheric measurements of nucleation as well as for laboratory studies of nucleation intending to simulate atmospheric conditions (i.e. $\left[\mathrm{H}_{2} \mathrm{SO}_{4}\right]<$ $1 \times 10^{7} \mathrm{~cm}^{-3}$ and $\mathrm{H}_{2} \mathrm{SO}_{4}$ sinks $>0.001 \mathrm{~s}^{-1}$, Kulmala et al., 2005).

When a significant sink is present, the nucleation rate has to be determined at the critical diameter to yield correct values of $n^{*}$. A correction from an apparent nucleation rate to the "true" nucleation rate can be impeded as the critical size is not a priori known.

\section{Methods}

The SAWNUC model was used to calculate the steady-state formation rate of particles exceeding a certain diameter at constant $\mathrm{H}_{2} \mathrm{SO}_{4}$ concentration, relative humidity and temperature. The calculation included particles up to a diameter of $3.5 \mathrm{~nm}$. A particle containing $i$ sulphuric acid molecules can undergo several processes that change the concentration $[i]$ of that particular species of particle.( For a detailed description of processes and their rate constants see Lovejoy et al. (2004) and Kazil and Lovejoy (2007).) Several processes change the concentration of $i$ clusters. Besides condensation and evaporation of $\mathrm{H}_{2} \mathrm{SO}_{4}$ molecules, these include coagulation with other charged or uncharged clusters, as well as coagulation with a fixed population of pre-existing aerosol particles and losses to reactor walls. To simulate conditions of a laboratory experiment of nucleation, the following loss term to simulate chamber walls was added to the equations of Lovejoy et al. (2004):

$L_{i}^{\mathrm{W}}=-k_{i}^{\mathrm{W}}[i]$.

Here $k_{i}^{\mathrm{w}}$ is described by

$k_{i}^{\mathrm{w}}=C \sqrt{D_{i}}$,

an approach already described in Metzger et al. (2010). The diffusion coefficient $D_{i}$ is a function of particle diameter and temperature and calculated by the Millikan-Cunninghamcorrected Stokes-Einstein diffusion (Baron and Willeke, 2001). The factor $C$ is chosen to produce the lifetime of $\mathrm{H}_{2} \mathrm{SO}_{4}$. Note that the diffusion coefficient of Hanson and Eisele (2000) for $\mathrm{H}_{2} \mathrm{SO}_{4}$ was not used in this calculation. The diffusion coefficient of sulphuric acid was calculated the same way as for particles, yielding a diffusion coefficient of $0.13 \mathrm{~cm}^{2} \mathrm{~s}^{-1}$, in order to have a consistent description of the size dependence rather than a consistent description of temperature dependence of $\mathrm{H}_{2} \mathrm{SO}_{4}$ diffusion.

It should be noted that losses to pre-existing particles or vessel walls are not equivalent to evaporation of sub critical clusters. The condensational sink effectively removes clusters and particles from the system, and thus is not contributing to the equilibrium before the critical cluster. This violates 
one of the most important assumptions of the nucleation theorem - the thermodynamic equilibrium of subcritical clusters.

For particle formation rates, $J_{d}$, at different mass diameters $d$, the number of $\mathrm{H}_{2} \mathrm{SO}_{4}$ molecules in the "apparent" critical cluster $n_{d}^{*}$ was calculated from

$n_{d}^{*} \approx \frac{\partial \log \left(J_{d}\right)}{\partial \log \left(\left[\mathrm{H}_{2} \mathrm{SO}_{4}\right]\right)}$.

It must be emphasised here that, strictly speaking, the critical cluster is given by $n^{*}=\partial \log \left(J_{d}\right) / \partial \log \left(\left[\mathrm{H}_{2} \mathrm{SO}_{4}\right]\right)-1$, (Ford, 1997; McGraw and Wu, 2003), though experimental studies often neglect the correction term and use the form of Eq. (3) (e.g. Metzger et al., 2010; Sipilä et al., 2010).

The particle formation rate represents the net flux of particles exceeding the diameter $d$ towards larger diameters. It is therefore equivalent to a formation rate as it would be measured by a particle counter with a step function counting efficiency that starts counting at $d \mathrm{~nm}$. If no additional losses occur, then $n_{d}^{*} \approx n^{*}$.

A kinetic approach to determine the critical cluster is described by Kazil and Lovejoy (2007). In the case of this method it is assumed that the critical cluster is the smallest cluster, for which

$k_{i}^{\mathrm{a}}\left[\mathrm{H}_{2} \mathrm{SO}_{4}\right] \geq k_{i}^{\mathrm{e}}$

is fulfilled. Here $k_{i}^{\mathrm{e}}$ is the rate constant of evaporation and $k_{i}^{\mathrm{a}}$ is the rate constant of sulphuric acid uptake. This approach is only valid for nucleation that is limited by a single freeenergy barrier.

In the case of additional losses (or source terms), the condition for a cluster where growth exceeds losses must be written as

$k_{i}^{\mathrm{a}}\left[\mathrm{H}_{2} \mathrm{SO}_{4}\right]+q_{i}^{\mathrm{c}} \geq k_{i}^{\mathrm{e}}+L_{i}^{\mathrm{c}}+L_{i}^{\mathrm{w}}$.

On the left-hand side, an additional source term was introduced that represents production of particles due to coagulation. On the right-hand side, $L_{i}^{\mathrm{c}}$ represents losses due to coagulation, while $L_{i}^{\mathrm{w}}$ is the wall loss term described above. Under most conditions, $q_{i}^{\mathrm{c}} \ll L_{i}^{\mathrm{c}}+L_{i}^{\mathrm{w}}$, this effectively increases the size of the "apparent" critical cluster.

Simulations were done at different conditions. The temperature was set to $248 \mathrm{~K}$, while the relative humidity was set to $40 \%$. At this temperature and relative humidity the effects of neutral and ion-induced nucleation (IIN) already overlap at intermediate $\mathrm{H}_{2} \mathrm{SO}_{4}$ concentrations. The ion pair production rate was set to 0 or 5 ion pairs $\mathrm{cm}^{-3} \mathrm{~s}^{-1}$, thus providing insight into the influence of ion-induced nucleation on the determination of $n_{d}^{*}$ and hence $n^{*}$. The lifetime of $\mathrm{H}_{2} \mathrm{SO}_{4}$ with respect to the walls, i.e. $\left(k_{\mathrm{H}_{2} \mathrm{SO}_{4}}^{\mathrm{w}}\right)^{-1}$, was varied to represent different laboratory conditions. Due to similarity between wall loss and condensation sink, the results can also be transferred to atmospheric conditions. Furthermore, two

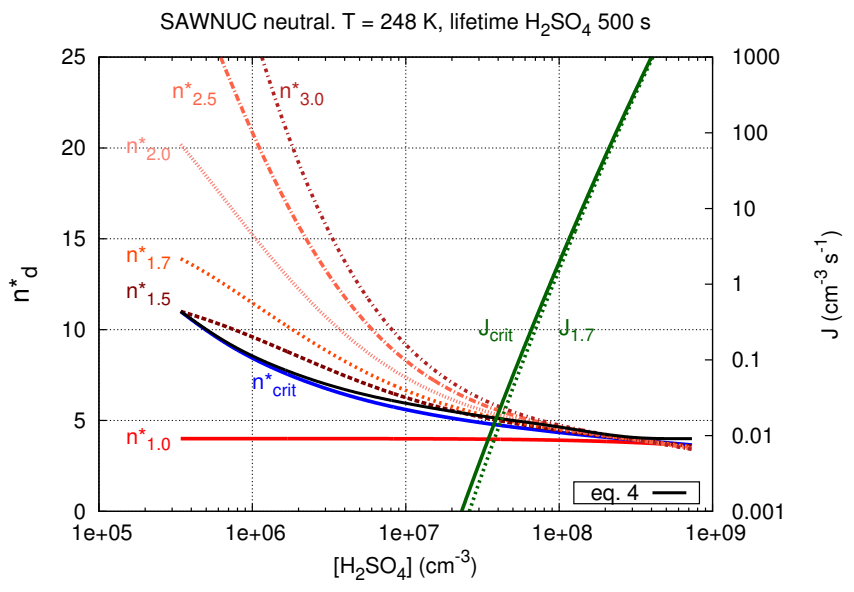

Fig. 1. Examples of the influence of different cut-off diameters on the interpretation of measurements of neutral particle formation rates at $T=248 \mathrm{~K}$ and $\mathrm{H}_{2} \mathrm{SO}_{4}$ lifetime of $500 \mathrm{~s}$. Red lines show $n_{d}^{*}$, and the blue lines show $n^{*}$ derived from Eq. (3). The black line shows $n^{*}$ from Eq. (4). The solid green line shows the "true" nucleation rate, while the dashed green line shows the formation rate of particles exceeding $1.7 \mathrm{~nm}$, i.e. the apparent nucleation rate. Values for both green lines can be taken from the right axis.

different free-energy surfaces were applied. In one case the original free energies (Lovejoy and Curtius, 2001; Curtius et al., 2001; Lovejoy et al., 2004) were used to determine the evaporation of particles; in another case, no evaporation was assumed, thus giving nucleation in the kinetic limit.

\section{Results}

Simulation results of $n_{d}^{*}$ derived from the sensitivity of $\log \left(J_{d}\right)$ to $\log \left(\mathrm{H}_{2} \mathrm{SO}_{4}\right)$ for $248 \mathrm{~K}$ with a $\mathrm{H}_{2} \mathrm{SO}_{4}$ lifetime of $500 \mathrm{~s}$ are shown in Fig. 1. The black line connects the integer numbers of $\mathrm{H}_{2} \mathrm{SO}_{4}$ molecules in the neutral critical cluster derived from Eq. (4); the blue line labelled $J_{\text {crit }}$ shows $n^{*}$ derived from the slope of the logarithm of the "true" nucleation rate. The red lines labelled $J_{d}$ show $n_{d}^{*}$ derived from formation rates of particles with mass diameter exceeding $d \mathrm{~nm}$. The green solid line shows the "true" nucleation rate, while the dashed green line shows the formation rate of particles with a diameter of $1.7 \mathrm{~nm}$. Both rates lie close each other, and for low concentrations of $\mathrm{H}_{2} \mathrm{SO}_{4}$, the value is too low to be measured. In this system the effect of walls or condensational sinks has therefore only minor influence on the interpretation of nucleation experiments in terms of the first nucleation theorem. In the case of a particle counter that measures subcritical clusters, here shown for a case of $1 \mathrm{~nm}$, the derived $n_{1.0}^{*}$ is independent of the $\mathrm{H}_{2} \mathrm{SO}_{4}$ concentration but is below the "true" $n$ * over a wide range of $\left[\mathrm{H}_{2} \mathrm{SO}_{4}\right]$. Although in this special system deviation of the derived $n_{d}^{*}$ from the "true" $n^{*}$ occurs mainly for nucleation rates too low to be measured, it can be used to test a simple rule to estimate how far 
results are biased by sinks. Similar approaches can be found in the literature (McGraw and Marlow, 1983; McMurry et al., 2005), but the description given here is more general and represents a widely applicable extension for experimental work under variable conditions. For this discussion we make use of characteristic times for the process of wall losses, i.e. the wall loss life time $\tau_{\mathrm{w}}$, and the time needed for nucleated particles to grow to detectable size $\tau_{\mathrm{g}}$. The lifetime in the simulation was $500 \mathrm{~s}$. At $\left[\mathrm{H}_{2} \mathrm{SO}_{4}\right]=1 \times 10^{8} \mathrm{~cm}^{-3}$ the deviation between the various $n_{d}^{*}$ and $n^{*}$ is low and the growth rate is in the range of a few $10 \mathrm{~nm} \mathrm{~h}^{-1}$ (Nieminen et al., 2010). If the nucleated particles have to grow $1 \mathrm{~nm}$ to be detected, then these $10 \mathrm{~nm} \mathrm{~h}^{-1}$ correspond to a $\tau_{\mathrm{g}}$ of about $400 \mathrm{~s}$. This example illustrates that

$\tau_{\mathrm{w}}>\tau_{\mathrm{g}}$

must be fulfilled in order to use the nucleation theorem with relatively good precision.

Vehkamäki et al. (2012) studied the effect of stable clusters smaller than the critical diameter on the interpretation of the nucleation theorem. This situation is given in the case of ion-induced nucleation. SAWNUC contains measured evaporation rates for negatively charged clusters (Curtius et al., 2001; Froyd and Lovejoy, 2003), and can therefore be used to study the effect of charged clusters on the nucleation theorem. The important feature of charged nucleation is that it provides a faster route to stable aerosols. This is achieved by a lower rate of evaporation and an enhanced rate of condensation due to charge dipole interactions of the charged cluster and the condensing $\mathrm{H}_{2} \mathrm{SO}_{4}$ ( $\mathrm{Su}$ and Chesnavich, 1982; $\mathrm{Yu}$ and Turco, 1998). After reaching a stable size, recombination with ions of opposite polarity yields stable neutral particles. The results of a simulation with an ion pair production rate of 5 ion pairs $\mathrm{cm}^{-3} \mathrm{~s}^{-1}$ are shown in Fig. 2. The black line corresponds to the amount of $\mathrm{H}_{2} \mathrm{SO}_{4}$ in the critical cluster based on neutral thermodynamics (Eq. 4). For most of the simulated particle formation rates, $n^{*}$ falls below the theoretically expected value for neutral nucleation at a certain $\mathrm{H}_{2} \mathrm{SO}_{4}$ concentration. For very high concentrations of $\mathrm{H}_{2} \mathrm{SO}_{4}$ the neutral line based on Eq. (4) and the lines derived from $J_{i}$ fall together. In these cases the neutral nucleation channel dominates and the contribution from the charged channel becomes insignificant. This effect can also be seen from the nucleation rate and the respective particle formation rate (green curves in Fig. 2). $J_{\text {crit }}$ and $J_{1.7}$ are at low concentration of $\mathrm{H}_{2} \mathrm{SO}_{4}$ mainly driven by ion-induced nucleation, the effect of ions decreases at $\left[\mathrm{H}_{2} \mathrm{SO}_{4}\right] \approx 1 \times 10^{7} \mathrm{~cm}^{-3}$ and in the case of insignificant neutral contribution, it would reach eventually the value of the ion pair production rate (see also Raes et al. (1986)). In this example the neutral nucleation starts to contribute to the total nucleation rate in the region of $\left[\mathrm{H}_{2} \mathrm{SO}_{4}\right]$ between $1 \times 10^{7}$ and $1 \times 10^{8} \mathrm{~cm}^{-3}$, and eventually becomes the main source of particle formation. For a particle counter with a threshold diameter $1 \mathrm{~nm}, n_{1.0}^{*}$ lies below the actual $n^{*}$

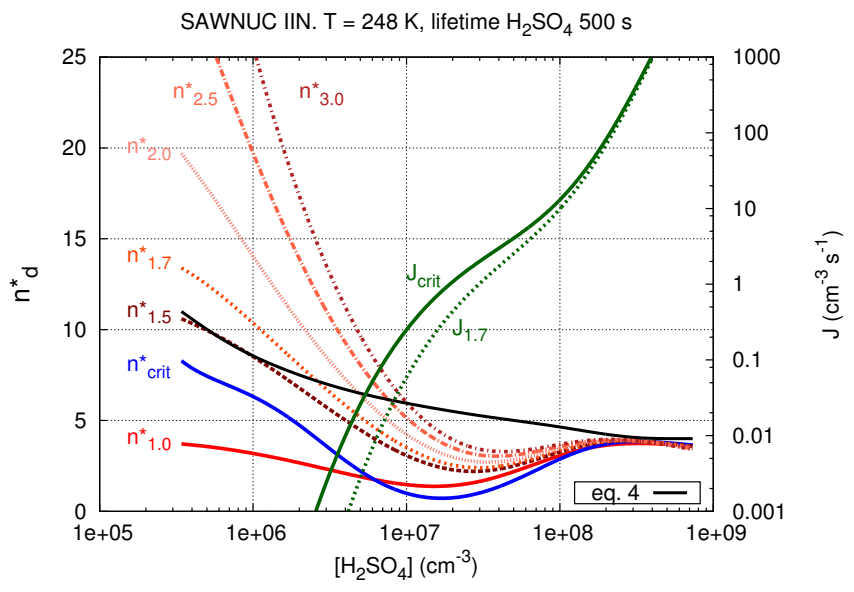

Fig. 2. Influence of an ion-induced nucleation channel and a sink for small particles on the interpretation of measurements of particle formation rates. The minimum in $n^{*}$ is around $1 \times 10^{7} \mathrm{~cm}^{-3}$ at 1.3. The labels and axis are the same as in Fig. 1.

for $\left[\mathrm{H}_{2} \mathrm{SO}_{4}\right]<1 \times 10^{7} \mathrm{~cm}^{-3}$. This changes when the critical diameter for the charged channel becomes smaller with higher $\left[\mathrm{H}_{2} \mathrm{SO}_{4}\right]$.

Recent research implies that nucleation under atmospheric conditions can proceed at or close to the kinetic limit, especially in the case of ternary nucleation (Metzger et al., 2010; Paasonen et al., 2012). Therefore the energy barrier in neutral nucleation was removed in SAWNUC and simulations under neutral conditions and varying concentrations of $\mathrm{H}_{2} \mathrm{SO}_{4}$ were performed. The lifetime of $\mathrm{H}_{2} \mathrm{SO}_{4}$ due to walls was set to $500 \mathrm{~s}$ as before. This gives reasonable approximation processes in ternary systems, with sulphuric acid being the vapour with the lowest concentration and therefore being the limiting species for growth and nucleation of particles. From Fig. 3 it can be seen that in such a system, strong deviations between the "true" $n *$ and the "apparent" $n_{d}^{*}$ also exist. These are also caused by the losses of the nucleating and growing clusters to walls or, in the case of atmospheric measurements, pre-existing particles. As in previous plots, the green curves show formation rates. While $J_{\text {crit }}$ follows a straight line with a slope of two as expected, $J_{1.7}$ shows a strong curvature depending on the concentration of $\mathrm{H}_{2} \mathrm{SO}_{4}$. Even in the case of the same slope, $J_{1.7}$ does not reach the same value as $J_{\text {crit }}$ due to self-coagulation of nucleating particles. Self-coagulation of nucleating particles was allowed in order to have a realistic description of nucleation in a clean experimental environment.

Simulation results for $n_{d}^{*}$ as function of the wall loss lifetime of $\mathrm{H}_{2} \mathrm{SO}_{4}$, for both $248 \mathrm{~K}$ and $\left[\mathrm{H}_{2} \mathrm{SO}_{4}\right]=2.3 \times$ $10^{6} \mathrm{~cm}^{-3}$, are shown in Fig. 4. Labels are the same as in the previous figure, and calculations were performed with evaporation rates removed. In the case of a wall loss and an environment free of pre-existing particles, $n_{d}^{*}$ from all formation rates basically match each other and $n_{d}^{*}=n^{*}$ for all $d$. The 


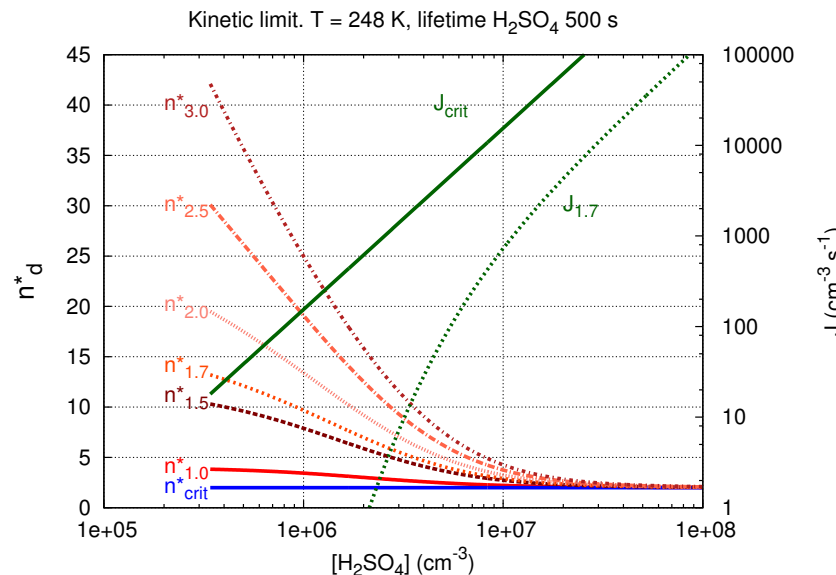

Fig. 3. Influence of a sink on the interpretation of measurements of particle formation rates in the case of kinetically limited nucleation. In such a system strong deviations between the "true" $n$ * (blue line) and the "apparent" $n_{d}^{*}$ (red lines) exist for the entire range of atmospherically relevant $\mathrm{H}_{2} \mathrm{SO}_{4}$ concentrations and nucleation rates. The labels and axis are the same as in Fig. 1.

deviation in $n^{*}$ between the different cut-offs increases linearly with increasing particle losses, with steeper increases for higher cut-offs. The comparison between the "true" nucleation rate, $J_{\text {crit }}$ green solid curve, and the formation rate of particles exceeding $1.7 \mathrm{~nm}, J_{1.7}$ green dashed curve, shows a big influence of wall losses. As mentioned above, neither green lines merge at $k^{\mathrm{w}}=0$ due to self-coagulation of the nucleating particles. $J_{1.7}$ shows a strong dependency on the wall loss rate and can suppress nucleation significantly, thus acting similar to an energy barrier and decreasing the particle formation rate significantly.

\section{Conclusions}

In this work it was shown that losses of small particles have to be taken into account when interpreting the slopes of a $\log \left(J_{d}\right)$ vs. $\log \left(\left[\mathrm{H}_{2} \mathrm{SO}_{4}\right]\right)$ plot. During the discussion phase of this paper it was pointed out that an independent study coming to a similar result (Malila et al., 2013) had been submitted to the International Conference on Nucleation and Atmospheric Aerosols (ICNAA). In laboratory experiments, flow tube or chamber, nucleating particles will be lost to the walls or removed from the vessel; in atmospheric measurements these particles will be lost to pre-existing larger aerosols. But these sinks differ from reactor to reactor, and in the atmosphere, pre-existing aerosol concentration and size distribution differ with time and location. Comparing results from different experiments can therefore lead to a bias in the interpretation of the experiment when these are interpreted in terms of the first nucleation theorem. This is especially valid when the "true" size of the critical cluster is not a priori known and the interpretation has to be based on formation

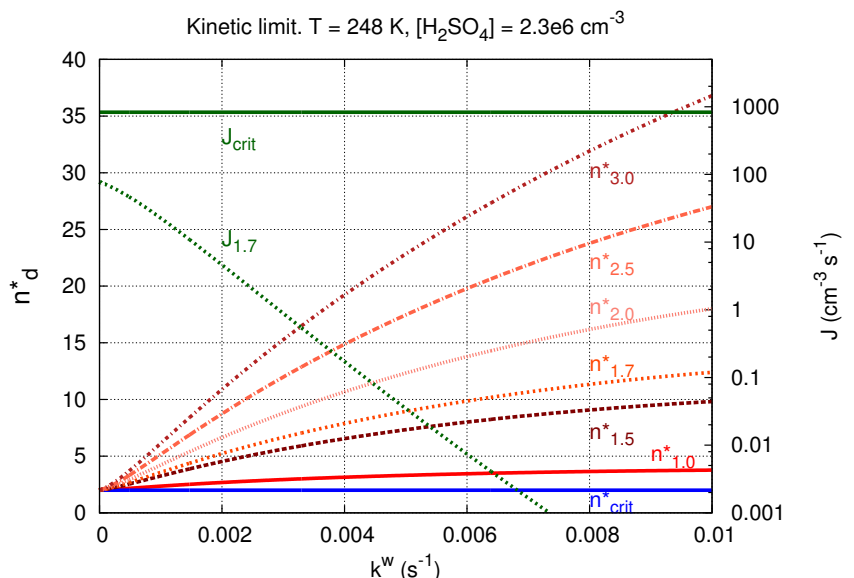

Fig. 4. $n_{d}^{*}$ vs. wall loss rate coefficient $k^{\mathrm{w}}$ for $\left[\mathrm{H}_{2} \mathrm{SO}_{4}\right]=2.3 \times$ $10^{6} \mathrm{~cm}^{-3}$ and no evaporation of nucleating particles. Labels are the same as in Fig. 1.

rates of particles exceeding a certain diameter. This bias can only be avoided when the growth rates are high enough so that the characteristic time of growing the particles is much smaller than the lifetime of the particles determined by the sink. Correcting measured formation rates to an assumed critical size can reduce this error, but assuming a critical size introduces another bias.

The situation becomes more complex in cases where another route to stable particles exists, for example ion-induced nucleation. Ternary nucleation that competes with binary nucleation is another factor that needs to be taken into account. And in even more complex cases ternary nucleation could proceed through different channels, depending on the availability and nature of condensable vapours. McGraw and $\mathrm{Wu}$ (2003) as well as McGraw and Zhang (2008) showed that in the case of ternary nucleation, the nucleation theorem can be applied when the sensitivity with respect to the concentration of condensing vapours is weighted by the flux. It must be noted that this approach requires that the binary and ternary nucleation rates are known and well separated; that is, the binary nucleation rate is not biased by contamination. Here it was shown that even in the simplest case of nucleation that is not limited by formation of a critical cluster interpreting the measurements in terms of the first nucleation theorem can give spurious results.

When interpreting a nucleation experiment in terms of the first nucleation theorem, the introduction of a sink appears to be similar to introducing small but significant evaporation to all clusters, although the microphysical difference between both processes remains. Therefore the results presented for this case can also be applied to nucleation without an energy barrier but with some evaporation. The condensational sink can also be seen as equivalent to a limited dwell time in a reactor. Especially flow tube reactors have typically short dwell times 
(e.g. Ball et al., 1999; Young et al., 2008; Zollner et al., 2012), and are therefore similar to systems with high condensational sinks.

Our overall conclusion is that the measured power dependency of nucleation rates on $\mathrm{H}_{2} \mathrm{SO}_{4}$ cannot be directly interpreted in terms of the number of $\mathrm{H}_{2} \mathrm{SO}_{4}$ molecules in the critical cluster, as suggested by the first nucleation theorem. It is therefore more appropriate to interpret the thermodynamics of such systems with microphysical models such as SAWNUC. A model describing nucleation from the growing monomer has the advantage of taking processes into account which are usually ignored in classical nucleation theory.

Acknowledgements. We thank Edward R. Lovejoy, Karl D. Froyd and Jan Kazil for providing the SAWNUC code. We further thank Eimear M. Dunne, Urs Baltensperger and Jasper Kirkby for useful discussions.

Edited by: A. Laaksonen

\section{References}

Ball, S. M., Hanson, D. R., Eisele, F. L., and McMurry, P. H.: Laboratory studies of particle nucleation: Initial results for $\mathrm{H}_{2} \mathrm{SO}_{4}$, $\mathrm{H}_{2} \mathrm{O}$, and $\mathrm{NH}_{3}$ vapors, J. Geophys. Res., 104, 23709-23718, doi:10.1029/1999JD900411, 1999.

Baron, P. A. and Willeke, K.: Aerosol Measurement, Wiley Interscience, United States of America, 2 Edn., 2001.

Becker, C. and Reiss, H.: Nucleation in a nonuniform vapor, J. Chem. Phys., 65, 2066-2070, doi:10.1063/1.433390, 1976.

Curtius, J., Froyd, K. D., and Lovejoy, E. R.: Cluster Ion Thermal Decomposition (I): Experimental Kinetics Study and ab Initio Calculations for $\mathrm{HSO}_{4}^{-}\left(\mathrm{H}_{2} \mathrm{SO}_{4}\right)_{\mathrm{x}}\left(\mathrm{HNO}_{3}\right)_{\mathrm{y}}$, J. Phys. Chem. A, 105, 10867-10873, doi:10.1021/jp0124950, 2001.

Curtius, J., Lovejoy, E., and Froyd, K.: Atmospheric Ioninduced Aerosol Nucleation, Space Sci. Rev., 125, 159-167, doi:10.1007/s11214-006-9054-5, 2006.

Ford, I. J.: Nucleation theorems, the statistical mechanics of molecular clusters, and a revision of classical nucleation theory, Phys. Rev. E, 56, 5615-5629, doi:10.1103/PhysRevE.56.5615, 1997.

Froyd, K. D. and Lovejoy, E. R.: Experimental Thermodynamics of Cluster Ions Composed of $\mathrm{H}_{2} \mathrm{SO}_{4}$ and $\mathrm{H}_{2} \mathrm{O}$. 2. Measurements and ab Initio Structures of Negative Ions, J. Phys. Chem. A, 107, 9812-9824, doi:10.1021/jp0278059, 2003.

Hanson, D. R. and Eisele, F.: Diffusion of $\mathrm{H}_{2} \mathrm{SO}_{4}$ in Humidified Nitrogen: Hydrated $\mathrm{H}_{2} \mathrm{SO}_{4}$, J. Phys. Chem. A, 104, 1715-1719, doi:10.1021/jp993622j, 2000.

Iida, K., Stolzenburg, M. R., and McMurry, P. H.: Effect of Working Fluid on Sub-2 nm Particle Detection with a Laminar Flow Ultrafine Condensation Particle Counter, Aerosol Sci. Tech., 43, 81-96, 2009.

Kashchiev, D.: On the relation between nucleation work, nucleus size, and nucleation rate, J. Chem. Phys., 76, 5098-5102, doi:10.1063/1.442808, 1982.

Kazil, J. and Lovejoy, E. R.: A semi-analytical method for calculating rates of new sulfate aerosol formation from the gas phase, At- mos. Chem. Phys., 7, 3447-3459, doi:10.5194/acp-7-3447-2007, 2007.

Kerminen, V.-M. and Kulmala, M.: Analytical formulae connecting the "real" and the "apparent" nucleation rate and the nuclei number concentration for atmospheric nucleation events, J. Aerosol Sci., 33, 609-622, doi:10.1016/S0021-8502(01)00194-X, 2002.

Kirkby, J., Curtius, J., Almeida, J., Dunne, E., Duplissy, J., Ehrhart, S., Franchin, A., Gagne, S., Ickes, L., Kürten, A., Kupc, A., Metzger, A., Riccobono, F., Rondo, L., Schobesberger, S., Tsagkogeorgas, G., Wimmer, D., Amorim, A., Bianchi, F., Breitenlechner, M., David, A., Dommen, J., Downard, A., Ehn, M., Flagan, R. C., Haider, S., Hansel, A., Hauser, D., Jud, W., Junninen, H., Kreissl, F., Kvashin, A., Laaksonen, A., Lehtipalo, K., Lima, J., Lovejoy, E. R., Makhmutov, V., Mathot, S., Mikkilä, J., Minginette, P., Mogo, S., Nieminen, T., Onnela, A., Pereira, P., Petäjä, T., Schnitzhofer, R., Seinfeld, J. H., Sipilä, M., Stozhkov, Y., Stratmann, F., Tomé, A., Vanhanen, J., Viisanen, Y., Vrtala, A., Wagner, P. E., Walther, H., Weingartner, E., Wex, H., Winkler, P. M., Carslaw, K. S., Worsnop, D. R., Baltensperger, U., and Kulmala, M.: Role of sulphuric acid, ammonia and galactic cosmic rays in atmospheric aerosol nucleation, Nature, 476, 429-433, 2011.

Kulmala, M., Vehkamäki, H., Petäjä, T., Maso, M. D., Lauri, A., Kerminen, V.-M., Birmili, W., and McMurry, P.: Formation and growth rates of ultrafine atmospheric particles: a review of observations, J. Aerosol Sci., 35, 143-176, doi:10.1016/j.jaerosci.2003.10.003, 2004.

Kulmala, M., Petäjä, T., Mönkkönen, P., Koponen, I. K., Dal Maso, M., Aalto, P. P., Lehtinen, K. E. J., and Kerminen, V.-M.: On the growth of nucleation mode particles: source rates of condensable vapor in polluted and clean environments, Atmos. Chem. Phys., 5, 409-416, doi:10.5194/acp-5-409-2005, 2005.

Lovejoy, E. R. and Curtius, J.: Cluster Ion Thermal Decomposition (II): Master Equation Modeling in the Low-Pressure Limit and Fall-Off Regions. Bond Energies for $\mathrm{HSO}_{4}^{-}\left(\mathrm{H}_{2} \mathrm{SO}_{4}\right)_{\mathrm{x}}\left(\mathrm{HNO}_{3}\right)_{\mathrm{y}}$, J. Phys. Chem. A, 105, 10874-10883, doi:10.1021/jp012496s, 2001.

Lovejoy, E. R., Curtius, J., and Froyd, K. D.: Atmospheric ioninduced nucleation of sulfuric acid and water, J. Geophys. Res.Atmos., 109, D08204, doi:10.1029/2003JD004460, 2004.

Malila, J., McGraw, R., Laaksonen, A., and Lehtinen, K. E. J.: Repairing the first nucleation theorem: Precritical cluster losses, AIP Conference Proceedings, 1527, 31-34, doi:10.1063/1.4803197, 2013.

McGraw, R. and Marlow, W. H.: The multistate kinetics of nucleation in the presence of an aerosol ${ }^{\mathrm{a}) \mathrm{b})}$, J. Chem. Phys., 78, 2542 2548, doi:10.1063/1.445007, 1983.

McGraw, R. and Wu, D. T.: Kinetic extensions of the nucleation theorem, J. Chem. Phys., 118, 9337-9347, doi:10.1063/1.1565098, 2003.

McGraw, R. and Zhang, R.: Multivariate analysis of homogeneous nucleation rate measurements. Nucleation in the p-toluic acid/sulfuric acid/water system, J. Chem. Phys., 128, 064508, doi:10.1063/1.2830030, 2008.

McMurry, P. H., Fink, M., Sakurai, H., Stolzenburg, M. R., Mauldin, R. L., Smith, J., Eisele, F., Moore, K., Sjostedt, S., Tanner, D., Huey, L. G., Nowak, J. B., Edgerton, E., and Voisin, D.: A criterion for new particle formation in the sulfur-rich Atlanta atmosphere, J. Geophys. Res.-Atmos., 110, D22S02, doi:10.1029/2005JD005901, 2005. 
Metzger, A., Verheggen, B., Dommen, J., Duplissy, J., Prevot, A. S. H., Weingartner, E., Riipinen, I., Kulmala, M., Spracklen, D. V., Carslaw, K. S., and Baltensperger, U.: Evidence for the role of organics in aerosol particle formation under atmospheric conditions, P. Natl. Acad. Sci. USA, 107, 6646-6651, 2010.

Nieminen, T., Lehtinen, K. E. J., and Kulmala, M.: Sub-10 nm particle growth by vapor condensation - effects of vapor molecule size and particle thermal speed, Atmos. Chem. Phys., 10, 97739779, doi:10.5194/acp-10-9773-2010, 2010.

Oxtoby, D. W. and Kashchiev, D.: A general relation between the nucleation work and the size of the nucleus in multicomponent nucleation, J. Chem. Phys., 100, 7665-7671, doi:10.1063/1.466859, 1994.

Paasonen, P., Olenius, T., Kupiainen, O., Kurtén, T., Petäjä, T., Birmili, W., Hamed, A., Hu, M., Huey, L. G., Plass-Duelmer, C., Smith, J. N., Wiedensohler, A., Loukonen, V., McGrath, M. J., Ortega, I. K., Laaksonen, A., Vehkamäki, H., Kerminen, V.-M., and Kulmala, M.: On the formation of sulphuric acid - amine clusters in varying atmospheric conditions and its influence on atmospheric new particle formation, Atmos. Chem. Phys., 12, 9113-9133, doi:10.5194/acp-12-9113-2012, 2012.

Raes, F. and Janssens, A.: Ion-induced aerosol formation in a $\mathrm{H}_{2} \mathrm{O}$ $\mathrm{H}_{2} \mathrm{SO}_{4}$ system - II. Numerical calculations and conclusions, J. Aerosol Sci., 17, 715-722, doi:10.1016/0021-8502(86)90051-0, 1986.

Raes, F., Janssens, A., and Dingenen, R. V.: The role of ion-induced aerosol formation in the lower atmosphere, J. Aerosol Sci., 17, 466-470, doi:10.1016/0021-8502(86)90135-7, 1986.

Sipilä, M., Berndt, T., Petäjä, T., Brus, D., Vanhanen, J., Stratmann, F.and Patokoski, J., Mauldin III, R. L., Hyvärinen, A.-P., Lihavainen, H., and Kulmala, M.: The role of sulfuric acid in atmospheric nucleation, Science, 327, 1243-1246, 2010.

$\mathrm{Su}$, T. and Chesnavich, W. J.: Parametrization of the ion-polar molecule collision rate constant by trajectory calculations, J. Chem. Phys., 76, 5183-5185, doi:10.1063/1.442828, 1982.

Vehkamäki, H., McGrath, M. J., Kurtén, T., Julin, J., Lehtinen, K. E. J., and Kulmala, M.: Rethinking the application of the first nucleation theorem to particle formation, J. Chem. Phys., 136, 094107, doi:10.1063/1.3689227, 2012.
Viisanen, Y., Kulmala, M., and Laaksonen, A.: Experiments on gasliquid nucleation of sulfuric acid and water, J. Chem. Phys., 107, 920-926, doi:10.1063/1.474445, 1997.

Weber, R. J., McMurry, P. H., Mauldin, R. L., Tanner, D. J., Eisele, F. L., Clarke, A. D., and Kapustin, V. N.: New Particle Formation in the Remote Troposphere: A Comparison of Observations at Various Sites, Geophys. Res. Lett., 26, 307-310, doi:10.1029/1998GL900308, 1999.

Wimmer, D., Lehtipalo, K., Franchin, A., Kangasluoma, J., Kreissl, F., Kürten, A., Kupc, A., Metzger, A., Mikkilä, J., Petäjä, T., Riccobono, F., Vanhanen, J., Kulmala, M., and Curtius, J.: Performance of diethylene glycol-based particle counters in the sub-3 nm size range, Atmos. Meas. Tech., 6, 1793-1804, doi:10.5194/amt-6-1793-2013, 2013.

Wyslouzil, B. E., Seinfeld, J. H., Flagan, R. C., and Okuyama, K.: Binary nucleation in acid-water systems. II. Sulfuric acid-water and a comparison with methanesulfonic acid-water, J. Chem. Phys., 94, 6842-6850, doi:10.1063/1.460262, 1991.

Young, L. H., Benson, D. R., Kameel, F. R., Pierce, J. R., Junninen, H., Kulmala, M., and Lee, S.-H.: Laboratory studies of $\mathrm{H}_{2} \mathrm{SO}_{4} / \mathrm{H}_{2} \mathrm{O}$ binary homogeneous nucleation from the $\mathrm{SO}_{2}+\mathrm{OH}$ reaction: evaluation of the experimental setup and preliminary results, Atmos. Chem. Phys., 8, 4997-5016, doi:10.5194/acp-84997-2008, 2008.

Yu, F. and Turco, R. P.: The formation and evolution of aerosols in stratospheric aircraft plumes: Numerical simulations and comparisons with observations, J. Geophys. Res., 103, 25915-25934, 1998.

Zollner, J. H., Glasoe, W. A., Panta, B., Carlson, K. K., McMurry, P. H., and Hanson, D. R.: Sulfuric acid nucleation: power dependencies, variation with relative humidity, and effect of bases, Atmos. Chem. Phys., 12, 4399-4411, doi:10.5194/acp-12-43992012, 2012. 